\title{
Multiple early gastric cancer with duodenal invasion
}

\section{Akihisa Matsuda*1,2, Shunji Kato ${ }^{2}$, Masaichi Furuya ${ }^{1}$, Yasuhito Shimizu ${ }^{1}$, Tetsuya Okino시 Junpei Sasaki ${ }^{1}$ and Takashi Tajiri²}

\author{
Address: ${ }^{1}$ Department of Surgery, Chikusei City Hospital, 1658 Tamado, Chikusei-shi, Ibaraki 308-0847, Japan and ${ }^{2}$ Surgery for Organ Function \\ and Biological Regulation (Department of Surgery), Graduate School of Medicine, Nippon Medical School, 1-1-5 Sendagi, Bunkyo-ku, Tokyo $113-$ \\ 8603, Japan \\ Email: Akihisa Matsuda* - a-matsu@nms.ac.jp; Shunji Kato - katoshun@nms.ac.jp; Masaichi Furuya - reno915@nms.ac.jp; \\ Yasuhito Shimizu - shimodate@nms.ac.jp; Tetsuya Okino - okino@nms.ac.jp; Junpei Sasaki - j-ssk@u01.gate01.com; \\ Takashi Tajiri - tajirit@nms.ac.jp \\ * Corresponding author
}

Published: 30 October 2007

World Journal of Surgical Oncology 2007, 5:125 doi:10.1/86/1477-7819-5-125

This article is available from: http://www.wjso.com/content/5/I/I25

(C) 2007 Matsuda et al; licensee BioMed Central Ltd.

This is an Open Access article distributed under the terms of the Creative Commons Attribution License (http://creativecommons.org/licenses/by/2.0), which permits unrestricted use, distribution, and reproduction in any medium, provided the original work is properly cited.
Received: 20 February 2007

Accepted: 30 October 2007

\begin{abstract}
Background: Early gastric cancers with duodenal invasion are rare, and no previous case of multiple early gastric cancer, one invading the duodenal bulb, has been reported.

Case presentation: A 79-year-old woman was investigated for upper abdominal discomfort. Endoscopic examination revealed an irregular nodulated lesion in the antrum area, and a reddish aggregated-type semi-circumferential nodulated lesion extending from the prepyloric area to the duodenal bulb through the normal mucosa with the antrum lesion. Biopsy revealed a tubular adenoma for the antrum lesion and a well-differentiated tubular adenocarcinoma for the prepyloric lesion. Distal gastrectomy with sufficient duodenal resection was performed. Microscopically, the antrum lesion appeared as a papillary adenocarcinoma, and the prepyloric lesion as a mainly papillary adenocarcinoma which partially invaded the submucosa without any sequential elongation for endoscopic findings. The lesion extended into the duodenal bulb, and was $12 \mathrm{~mm}$ in length from the oral end of Brunner's gland's area and limited within the duodenal mucosa.

Conclusion: Here, we present an unusual case of multiple early gastric cancer, one of which invaded the duodenum with relative wide mucosal spreading. This case illustrates that even early stage cancers located in the gastric antrum, particularly in the prepyloric area can invade the duodenum directly.
\end{abstract}

\section{Background}

Advanced gastric cancer of the antrum occasionally invades the duodenum beyond the pyloric ring. These cases are reported to have a poor prognosis $[1,2]$. However, early gastric cancers with duodenal invasion are rare, with an incidence ranging from $0.5 \%$ to $1.8 \%$ of all gastric cancer cases [3-5]. In this report, we describe a patient with two early gastric cancers, one of which invaded the duodenal bulb, and discuss the clinicopathological features of early gastric cancer cases with duodenal invasion.

\section{Case presentation}

A 79-year-old Japanese woman complained of upper abdominal discomfort during postoperative follow-up for breast cancer in March 2005. She had no remarkable past history other than breast cancer and her relatives have not 
been suffered no malignant diseases. On physical findings, her temperature was $36.6^{\circ} \mathrm{C}$, and there was no palpable abdominal mass. No sign of lymphadenopathy was found. Initial laboratory testing revealed no abnormalities other than a high serum concentration of CA19-9 (42.4 $\mathrm{U} / \mathrm{ml}$; normal, <37 U/ml) (Table 1). Endoscopic examination revealed an irregular nodulated lesion in the antrum area (Figure 1a), and a reddish aggregated-type semi-circumferential nodulated lesion extending from the prepyloric area to the duodenal bulb through the normal mucosa with the antrum lesion (Figure 1b). The biopsy specimens revealed a tubular adenoma from the antrum lesion and a well-differentiated tubular adenocarcinoma from the prepyloric lesion. A double-contrast picture showed an irregular nodulated lesion extending from the prepyloric area to the duodenal bulb; however, no hardening of the gastric wall was detected on barium study (Figure 2). Metastatic workup was negative. Distal gastrectomy with sufficient distal surgical margin, $30 \mathrm{~mm}$ from pyloric ring, and lymph node dissection (D2) was performed in April 2005. We adopted Roux-en Y reconstruction which is capable of cancer free anastomosis even if duodenal resection reached broad. The intraoperative distal surgical margin was negative. Macroscopically, the resected specimen showed two independent polypoid lesions, an oral-side lesion of $70 \times 40 \mathrm{~mm}$ located in the antrum area extending superficially and an anal-side semi-circumferential lesion of $70 \times 25 \mathrm{~mm}$ located mainly in the prepyloric area and duodenal bulb beyond the pyloric ring. The intervening mucosa between the two lesions was normal (Figure 3ab).

The resected specimen was examined histologically to determine the depth and mode of invasion, metastasis to lymph nodes, histologic type, and invasion to the duodenum according to the general rules established by the Japanese Gastric Cancer Association [6]. Microscopically, the antrum lesion showed a papillary adenocarcinoma with high-grade atypia limited within the gastric mucosa without vessel invasion (Figure 4a). The prepyloric lesion showed a mainly papillary adenocarcinoma mixed with tubular and villous formations which partially invaded the submucosa without vessel invasion (Figure $4 \mathrm{~b}$ ). The cancerous lesion extended into the duodenal bulb, and was $12 \mathrm{~mm}$ in length from the oral end of Brunner's gland's area, and limited within the duodenal mucosa. This lesion showed an identical histology to the prepyloric part (Figure 4c). The two lesions were classified as intestinal type and separated by at least $20 \mathrm{~mm}$ of intervening normal mucosa. The back ground mucosa of these lesions was mild atrophic gastritis and intestinal metaplasia. Helicobacter pylori infection was detected by histological findings. The distal margin of the surgical specimen, $4 \mathrm{~mm}$ in length, was negative. A schematic representation of the resected specimen is shown in Figure 5. No dissected lymph nodes showed metastasis. We finally diagnosed the lesions as two early gastric cancers, as follows. Antrum lesion: L, pap, type 0 I, pT1(M), ly0, v0,

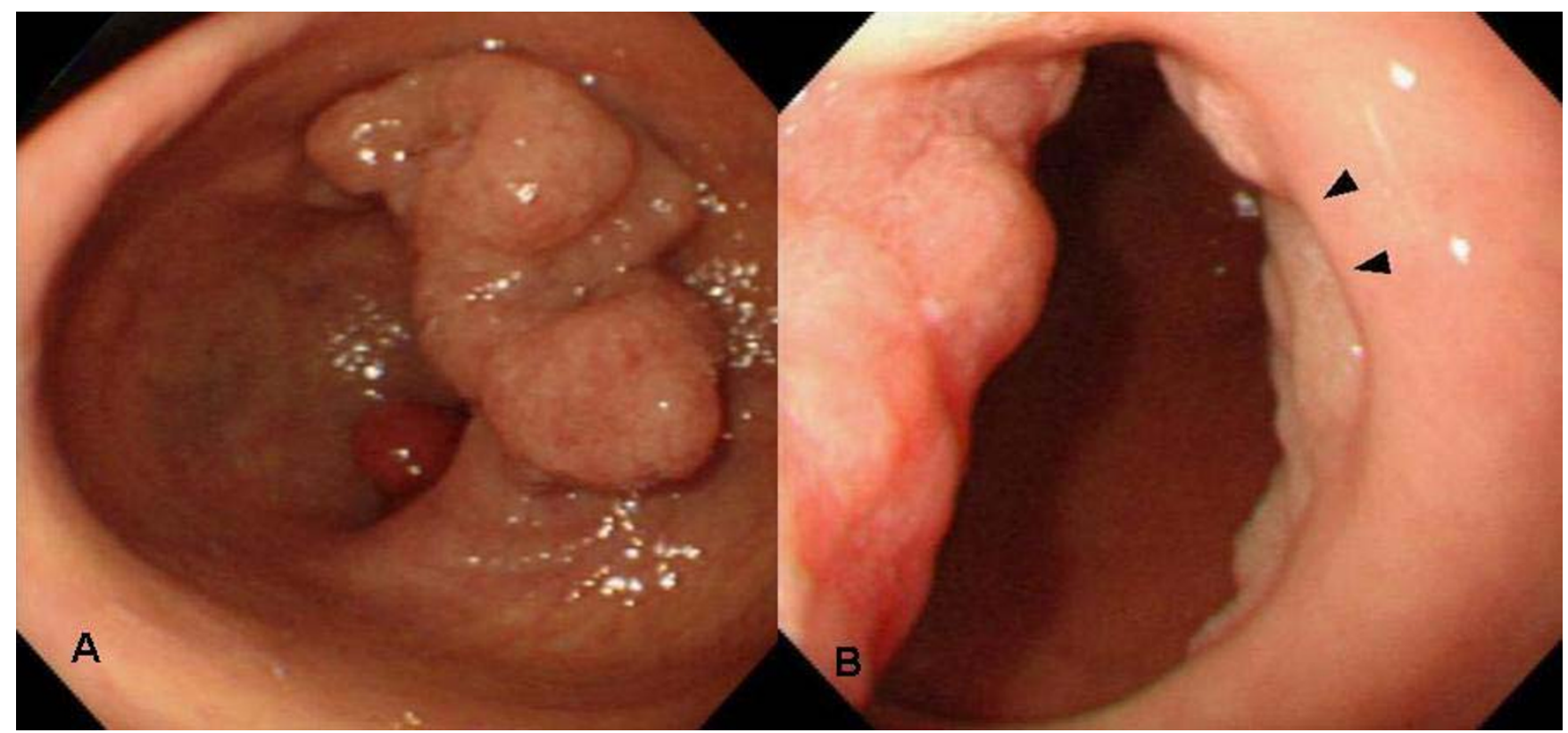

Figure I

a, b. Endoscopic examination showed an irregular nodulated lesion in the antrum area (a) and a reddish aggregated-type semicircumferential nodulated lesion extending from the prepyloric area to duodenal bulb through the normal mucosa with the former lesion (arrowheads show the p-ring) (b). 


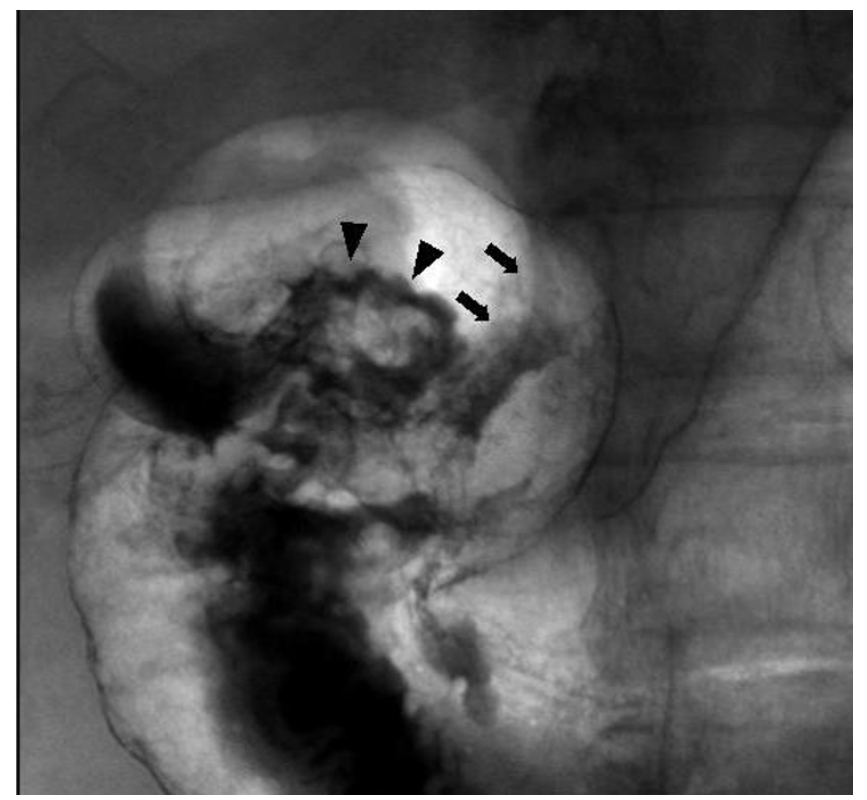

Figure 2

The double-contrast picture showed an irregular nodulated lesion from the prepyloric area to the duodenal bulb (arrowheads show extension to the duodenal bulb. arrows show the p-ring)

pPM(-), pDM(-), pN0, sH0, sP0, sM0, CY0; and prepyloric lesion: LD, pap, type 0 I, pT1(SM), ly0, v0, pPM(-), pDM(-), pN0, sH0, sP0, sM0, CY0, stage IA. The postoper- ative course was uneventful and the patient was discharged 38 days after admission. No recurrence or metastasis has been detected during three years of followup after the operation.

\section{Discussion}

Here, we present an unusual case of multiple early gastric cancer, one of which invaded the duodenum with relative wide mucosal spreading. Although advanced gastric cancer with duodenal invasion is widely reported, cases of early gastric cancer with duodenal invasion are rare, with an incidence ranging from $0.5 \%$ to $1.8 \%$ of all gastric cancer cases [3-5]. 34 cases of early gastric cancer with duodenal invasion have been reported previously, to our knowledge, no case of multiple early gastric cancer has been reported (Table 2). Multiple gastric cancer is defined generally by Moertel's criteria [7]. Moertel reported the incidence of multiple gastric cancer is $2.1 \%$. Recently, the incidence is increasing up to $6 \%$ approximately with an improvement of diagnostic technique [8].

Clinically, definition of the border between the stomach and the duodenum is contentious. Although the pyloric ring is composed of gastric tissue macroscopically, Brunner's glands are present beginning in the mucosa over the pyloric ring. Clinicopathological studies of duodenal invasion suggest the duodenum starts at the point where Brunner's glands first occur $[4,9]$. The pyloric ring is the contact point between two different types of mucosa;

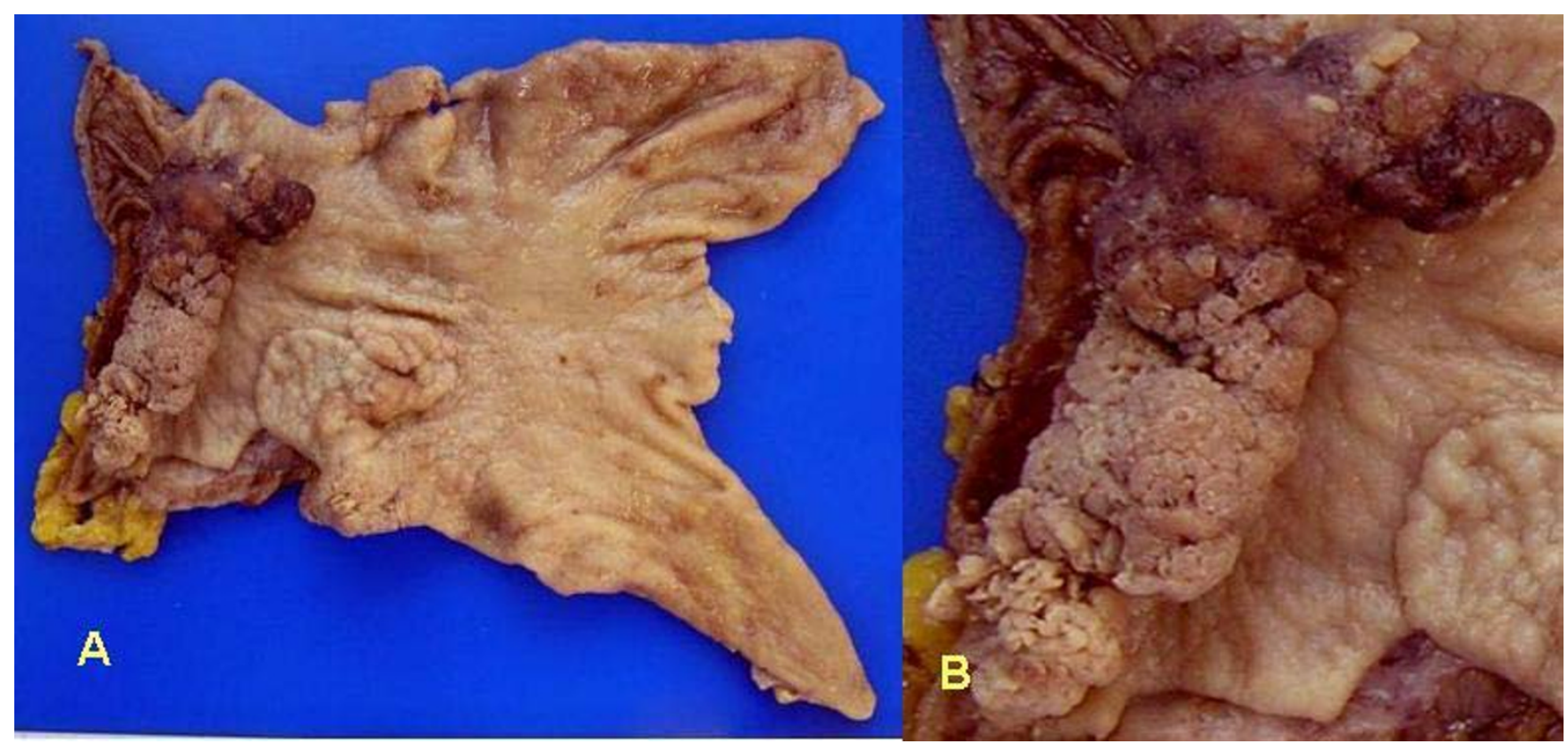

Figure 3

a, b. Microscopically, the resected specimen showed two independent irregular nodulated lesions. The oral-side lesion extending superficially, is located in the antrum area and is $70 \times 40 \mathrm{~mm}(\mathrm{a})$. The anal-side semi-circumferential lesion is $70 \times 25 \mathrm{~mm}$ and located mainly in the prepyloric area and duodenal bulb beyond the pyloric ring (b). 
Table I: Laboratory data on admission

\begin{tabular}{llll}
\hline Laboratory parameter & Value & Parameter & Value \\
\hline White blood count & $42 \times 10^{2} / \mu \mathrm{L}$ & Total bilirubin & $1.1 \mathrm{mg} / \mathrm{dL}$ \\
Red cell count & $415 \times 10^{4} / \mu \mathrm{L}$ & Sodium & $142 \mathrm{mEq} / \mathrm{L}$ \\
Hemoglobin & $13.2 \mathrm{gm} / \mathrm{dL}$ & Potassium & $4.1 \mathrm{mEq} / \mathrm{L}$ \\
Hematocrit & $39.6 \%$ & Chloride & $103 \mathrm{mEq} / \mathrm{L}$ \\
Platelets & $22.5 \times 104 / \mu \mathrm{L}$ & Blood urea nitrogen & $17.5 \mathrm{mg} / \mathrm{dL}$ \\
SGOT & $36 \mathrm{IU} / \mathrm{L}$ & Creatinine & $0.7 \mathrm{mg} / \mathrm{dL}$ \\
SGPT & $34 \mathrm{IU} / \mathrm{L}$ & Total protein & $7.7 \mathrm{gm} / \mathrm{dL}$ \\
LDH & $206 \mathrm{IU} / \mathrm{L}$ & Albumin & $4.7 \mathrm{gm} / \mathrm{dL}$ \\
Amylase & $111 \mathrm{IU} / \mathrm{L}$ & C reactive protein & $0.03 \mathrm{mg} / \mathrm{dL}$ \\
CPK & $216 \mathrm{IU} / \mathrm{L}$ & CEA & $1.2 \mathrm{ng} / \mathrm{ml}$ \\
CA 19-9 & $42.4 \mathrm{U} / \mathrm{L}$ & & \\
\hline
\end{tabular}

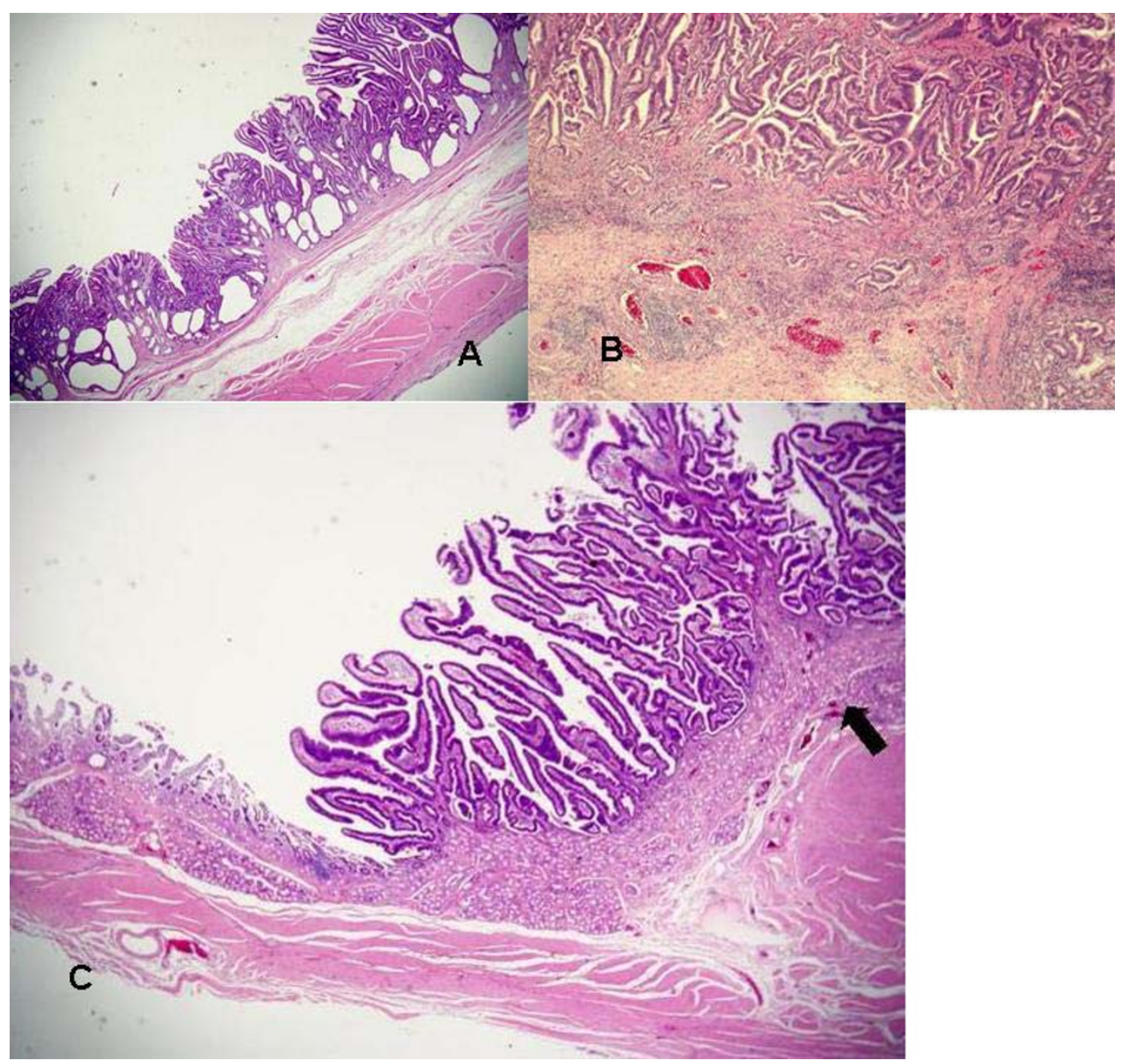

\section{Figure 4}

a-c. Microscopically, the antrum lesion showed a well-differentiated papillary adenocarcinoma limited within the gastric mucosa (HE stain. $\times$ I0) (a). The prepyloric lesion showed a mainly well-differentiated papillary adenocarcinoma partially invading the submucosa $($ HE stain. $\times 20)(\mathbf{b})$. The lesion extending into the duodenal bulb was limited within the duodenal mucosa and showed an identical histology to the prepyloric part (HE stain. $\times 10)$. The arrow shows the beginning of Brunner's glands (c). 


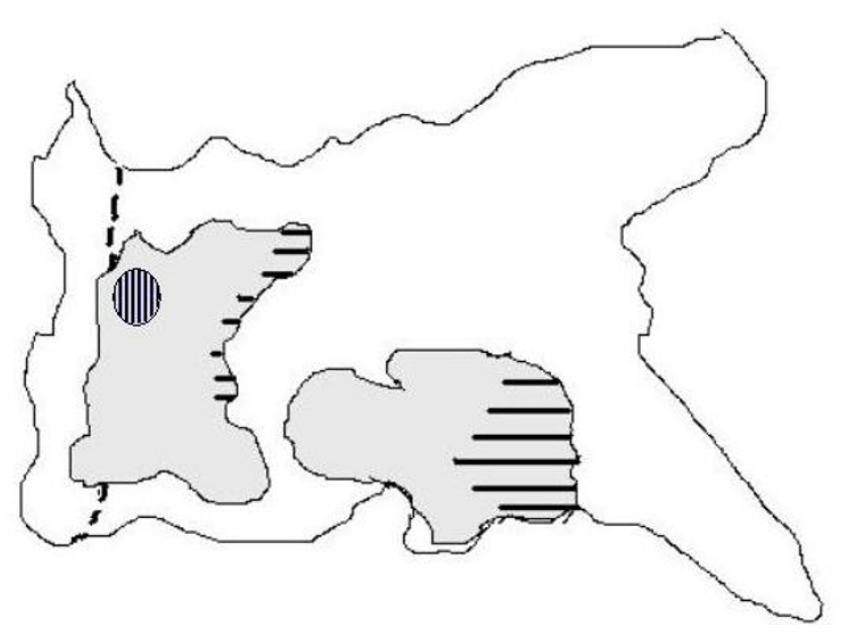

Figure 5

Schematic representation of the resected specimen. Horizontal lines show adenoma components of each tumor. Vertical lines show submucosal invasion of the prepyloric lesion, while dotted lines show the pyloric ring.

hence, Brunner's glands seem to act as a protective barrier against cancer invasion [4]. Another report showed that the presence of extremely dense connective fibers in the subepithelial proper mucosal layer can prevent the direct extension of mucosal carcinoma into the duodenum [10]. These theories are thought to explain the rarity of early gastric cancer with duodenal invasion, at least in part [11]. However, the increasing number of such cases attests to the ability of it gastric cancer cells can to directly invade the duodenum in the mucosal layer $[4,12]$. Our case also showed direct mucosal invasion into the duodenum.

Preoperative diagnosis of early gastric cancer with duodenal invasion is difficult. Nakayama et al. [13] reviewed 24 cases in Japan and found that duodenal invasion was preoperatively detectable in only four, all of which were welldifferentiated and of the elevated type. The microscopic extension of cancer cells in poorly-differentiated cases is often infiltrative and broader than the macroscopic extension, hampering the detection of duodenal invasion of poorly differentiated early gastric cancer, particularly for small lesions.

Regarding the length of duodenal invasion, most early gastric cancer cases reported to date have shown invasion of less than $10 \mathrm{~mm}[3,13]$. This is another reason for the difficulty of detecting duodenal invasion preoperatively. In our case, however, invasion extended $12 \mathrm{~mm}$ into the duodenum from the beginning point of Brunner's glands. Uchida et al. [14] reported that papillary-type gastric cancer cells have a high affinity for the duodenal mucosa and that papillary-type gastric adenocarcinoma occasionally shows transient formation in the duodenal mucosa. These findings may help explain the broad duodenal invasion of over $10 \mathrm{~mm}$ in our case. Besides, most cases of early gastric cancer with duodenal invasion is limited to the mucosal layer of the duodenum, only 2 cases with submucosal invasion into the duodenum have been reported previously (Table 2). The cases of submucosal invasion into the duodenum do not always show the longer invasion into duodenum compared with mucosal invasion cases. This finding indicates that, as in the reported advanced cases with duodenal invasion, the depth of duodenal invasion does not independently affect the length of duodenal invasion [14]. Therefore, these imply us that, it is difficult to anticipate the extent of duodenal invasion, pre and intra operative close observation for duodenal invasion is indispensable to keep the distal surgical margin negative with sufficient duodenal resection.

Koufuji et al. [3] reported four cases of early gastric cancer with duodenal invasion which showed lymph node metastasis. All the four cases showed just one regional lymph node metastasis. Three of four cases metastasize to No. 6 and one case to No. 12 lymph node. Nevertheless, the small number of reported cases has prevented any clear understanding of whether early gastric cancer with duodenal invasion has a higher incidence of lymph node metastasis than that without duodenal invasion. Although the reported incidence of lymph node metastasis from early gastric cancer with submucosal invasion is approximately $20 \%$, our present case showed no metastasis [15].

\section{Conclusion}

A greater number of cases should help clarify the clinicopathological findings of early gastric cancer with duodenal invasion. The present case emphasizes that even early stage cancers located in the gastric antrum, particularly in the prepyloric area can invade the duodenum directly.

\section{Competing interests}

The author(s) declare that they have no competing interests. 
Table 2: Reported cases early gastric cancer with duodenal invasion

\begin{tabular}{|c|c|c|c|c|c|c|c|c|}
\hline Authors & Year & Size $(\mathrm{mm})$ & Location & Length of invasion (mm) & Histologic type (duodenum) & Type & Depth (duodenum) & $\mathrm{N}$ \\
\hline \multirow[t]{2}{*}{ Ishii } & 1975 & & LD, Circ & 7 & Tub & Depressed & $\mathrm{m}(\mathrm{m})$ & 0 \\
\hline & & $30 \times 15$ & LD & 5 & Pap & Elevated & $\mathrm{sm}(\mathrm{m})$ & 0 \\
\hline Kuwayama & 1976 & $40 \times 35$ & $\mathrm{LD}$, ant-less & & Pap (por) & Depressed & $\mathrm{m}(\mathrm{m})$ & 0 \\
\hline \multirow[t]{3}{*}{ Uchida } & 1979 & $32 \times 25$ & LD, Circ & 7 & Por & Depressed & $\mathrm{m}(\mathrm{m})$ & 0 \\
\hline & & $35 \times 21$ & LD & 2 & Tubl & Mixed & $\mathrm{sm}(\mathrm{sm})$ & 0 \\
\hline & & $30 \times 15$ & LD & 5 & Pap & Elevated & $\mathrm{sm}(\mathrm{m})$ & 0 \\
\hline \multirow[t]{7}{*}{ Kuwata } & 1981 & & LD, less & 5 & $\mathrm{Sig}$ & Depressed & $\operatorname{sm}(\mathrm{m})$ & 0 \\
\hline & & & LD, gre & 6 & Tubl (pap) & Elevated & $\mathrm{sm}(\mathrm{m})$ & 0 \\
\hline & & & LD, less & 2 & Pap & Elevated & $\mathrm{sm}(\mathrm{m})$ & 0 \\
\hline & & & LD post & I & Tub2 & Mixed & $\mathrm{sm}(\mathrm{m})$ & 0 \\
\hline & & $30 \times 15$ & LD, less & 2 & Tub2 & Mixed & $\mathrm{sm}(\mathrm{m})$ & 0 \\
\hline & & $35 \times 21$ & LD, less & I & Tub2 & Depressed & $\mathrm{sm}(\mathrm{m})$ & 0 \\
\hline & & $30 \times 15$ & LD, less & 5 & Pap & Mixed & $\mathrm{sm}(\mathrm{m})$ & 0 \\
\hline Katoh & 1993 & $68 \times 36$ & LD, circ & 16 & Tubl (pap) & Elevated & $\mathrm{m}(\mathrm{m})$ & 0 \\
\hline Nakazawa & 1994 & $10 \times 10$ & LD, ant-gre & 3 & Tubl & Depressed & $\mathrm{m}(\mathrm{sm})$ & 0 \\
\hline Boku & 1996 & 70 & LD, circ & 40 & Tubl & Elevated & $\operatorname{sm}(m)$ & 0 \\
\hline Itoh & 1996 & $45 \times 35$ & LD, less & 25 & Tubl (pap) & Mixed & $\mathrm{sm}(\mathrm{m})$ & 0 \\
\hline \multirow[t]{5}{*}{ Matsumoto } & 2000 & $25 \times 9$ & LD, less & 3 & Sig & Elevated & $\mathrm{m}$ & \\
\hline & & $25 \times 10$ & LD, gre-post & 10 & Sig & Elevated & $\mathrm{sm}$ & \\
\hline & & $30 \times 13$ & & 3 & Mod & Elevated & $\mathrm{m}$ & \\
\hline & & $65 \times 23$ & & 3 & Mod & Elevated & $\mathrm{m}$ & \\
\hline & & $45 \times 45$ & & 5 & Mod & Superficial & sm & \\
\hline Yasuda & 2000 & $75 \times 15$ & LD, circ & 11 & Sig(por) & Depressed & $\mathrm{m}(\mathrm{m})$ & 0 \\
\hline Nakayama & 2001 & $85 \times 75$ & LD circ & 38 & Tubl & Mixed & $\mathrm{sm}(\mathrm{m})$ & 0 \\
\hline \multirow[t]{10}{*}{ Koufuji } & 2003 & $70 \times 50$ & LD circ & 2 & Tubl & Mixed & sm & 0 \\
\hline & & $90 \times 55$ & LD, circ & 2 & Tubl & Elevated & $\mathrm{sm}$ & 0 \\
\hline & & $120 \times 98$ & LMD, circ & 2 & Sig & Depressed & $\mathrm{m}$ & 0 \\
\hline & & $103 \times 102$ & LMD, circ & 8 & Sig & Depressed & $\mathrm{m}$ & 0 \\
\hline & & $55 \times 24$ & LD, less & 3 & Sig & Depressed & $\mathrm{sm}$ & I \\
\hline & & $30 \times 20$ & LD gre & 2 & Tubl & Depressed & $\mathrm{sm}$ & I \\
\hline & & $52 \times 30$ & LD, less & 5 & Tub2 & Depressed & $\mathrm{sm}$ & 0 \\
\hline & & $57 \times 33$ & LD circ & 3 & Sig & Depressed & $\mathrm{m}$ & 0 \\
\hline & & $40 \times 38$ & LD gre & 5 & Por2 & Depressed & $\mathrm{sm}$ & I \\
\hline & & $80 \times 65$ & LD, circ & 2 & Sig & Depressed & sm & 2 \\
\hline Our case & 2007 & $30 \times 15$ & LD, circ & 12 & Pap & Elevated & $\mathrm{sm}(\mathrm{m})$ & 0 \\
\hline
\end{tabular}

\section{Authors' contributions}

$\mathrm{AM}, \mathrm{YS}, \mathrm{TO}$, JS and MF carried out the surgical procedures. SK and TT revised and finally approved the manuscript for been published. All authors read approved the final version of the manuscript.

\section{Acknowledgements}

Written informed consent was obtained from the patient for publication of the case report.

\section{References}

I. Nishi M, Nakamura M, Sekiguchi T, Motoki T, Ohyama O, Kinoshita I: Invasion of gastric carcinoma into the duodenum and its operative result. Operation 1966, 20:986-996. (in Japanese)

2. Kakeji $Y$, Korenaga D, Baba H, Watanabe A, Tsujitani S, Maehara $Y$, Sugimachi K: Surgical treatment of patients with gastric carcinoma and duodenal invasion. J Surg Oncol 1995, 59:2 15-219.
3. Koufuji K, Takeda J, Aoyagi K, Yano S, Miyagi M, Koga A, Shirouzu K: Clinicopathological study of early gastric cancers with duodenal invasion. Jpn J Cancer Clin 2003, 49:2 I I-2 I3. (in Japanese)

4. Kakeji Y, Tsujitani S, Baba H, Moriguchi S, Mori M, Maehara Y, Kamegawa $T$, Sugimachi K: Clinicopathological features and prognostic significance of duodenal invasion in patients with distal gastric carcinoma. Cancer 1991, 68:380-384.

5. Ishikawa M, Kitayama J, Fujii S, Ishigami H, Kaizaki S, Nagawa H: Recurrent intramucosal gastric carcinoma with extensive invasion to duodenal mucosa after endoscopic mucosal resection: A case report. Am Surg 2005, 4:366-368.

6. Japanese Gastric Cancer Association: Japanese Classification of Gastric Carcinoma -2nd English Edition. Gastric cancer 1998, I:I0-24.

7. Moertel CG, Bargen JA, Soule EH: Multiple gastric cancer Review of the literature and study of $\mathbf{4 2}$ cases. Gastroenterology 1959, 32:1095-1103.

8. Yanadori E, Oguma H, Sasagawa T, Kitamura Y, Takasaki K: Clinicopathological study of multiple gastric cancer. Jpn J Gastroenterol Surg 200I, 34:9-14. (in Japanese)

9. Ohta J, Kodama I, Takamiya H, Mizutani K, Yano S, Aoyagi K, Koufuji K, Takeda J, Shirouzu K: A clinicopathological study of distal advanced gastric carcinoma with duodenal invasion. Kurume Med J 1996, 43:189-198.

10. Shimizu H: Communication between the stomach wall and the duodenal wall, especially the route of infiltration of gas- 
tric cancer into the duodenum. Nippon Geka Hokan 1959:1334-1355. (in Japanese)

II. Ohara T, Ihara O: Duodenal invasion of gastric cancer. Prog of Dig Endosc 1983, 22:31-35. (in Japanese)

12. Kuwata H, Katsumata T, Saigenji K, Okabe H, Hiki Y, Ohida M, Atari $\mathrm{H}$, Mieno $\mathrm{H}$ : Histological study on the extension of early gastric cancer into the duodenum. Prog of Dig Endosc 1981, 18:124-127. (in Japanese)

13. Nakayama Y, Kadowaki K, Hirata K, Higure A, Nagata N, Itoh H: A case report of early gastric cancer with duodenal extension. Jpn J Gastroenterol Surg 2004, 37:506-5I I. (in Japanese)

14. Uchida U, Nogawa T, Yamashita M, Hashimoto S, Fujii R, Azekura K, Hashimoto $Y$, Ishikawa $Y$, Kotake $Y$, Ino M, Hidaka S, Kitasato S, Ooe H, Shibata O, Ishii T, Shimoyama T, Miura T, Tsuji Y, Sekine I: Clinicopathological studies on carcinoma invading in stomach and duodenum. Jpn J Gastroenterol Surg 1979, I 2:89|-900. (in Japanese)

15. Shimada S, Yagi Y, Shiomori K, Honmyo U, Hayashi N, Matsuo A, Marutsuka T, Ogawa M: Characterization of early gastric cancer and proposal of the optimal therapeutic strategy. Surgery 200I, I29:7|4-7I9.

Publish with Bio Med Central and every scientist can read your work free of charge

"BioMed Central will be the most significant development for disseminating the results of biomedical research in our lifetime. "

Sir Paul Nurse, Cancer Research UK

Your research papers will be:

- available free of charge to the entire biomedical community

- peer reviewed and published immediately upon acceptance

- cited in PubMed and archived on PubMed Central

- yours - you keep the copyright

Submit your manuscript here:

http://www.biomedcentral.com/info/publishing_adv.asp 